\title{
An Usual Cause of Intermittent Dysphagia
}

\author{
Moon Won Lee', Gwang Ha Kim ${ }^{1,2}$
}

Department of Internal Medicine, Pusan National University School of Medicine ${ }^{1}$, Biomedical Research Institute, Pusan National University Hospital $^{2}$, Busan, Korea

Question: A 58-year-old man presented with a 1-year history of intermittent dysphagia and globus sensation. Upper endoscopy revealed a huge, sausage-shaped mass originating from the cervical esophagus (Fig. 1A). The mass was pulled into the oral cavity during examination (Fig. 1B). Endoscopic ultrasonography revealed a hetero- geneously hyperechoic lesion located at the submucosal layer of the esophagus (Fig 1C). Endoscopic resection was performed using a snare without complications such as bleeding (Fig. 1D).

What is the most likely diagnosis?
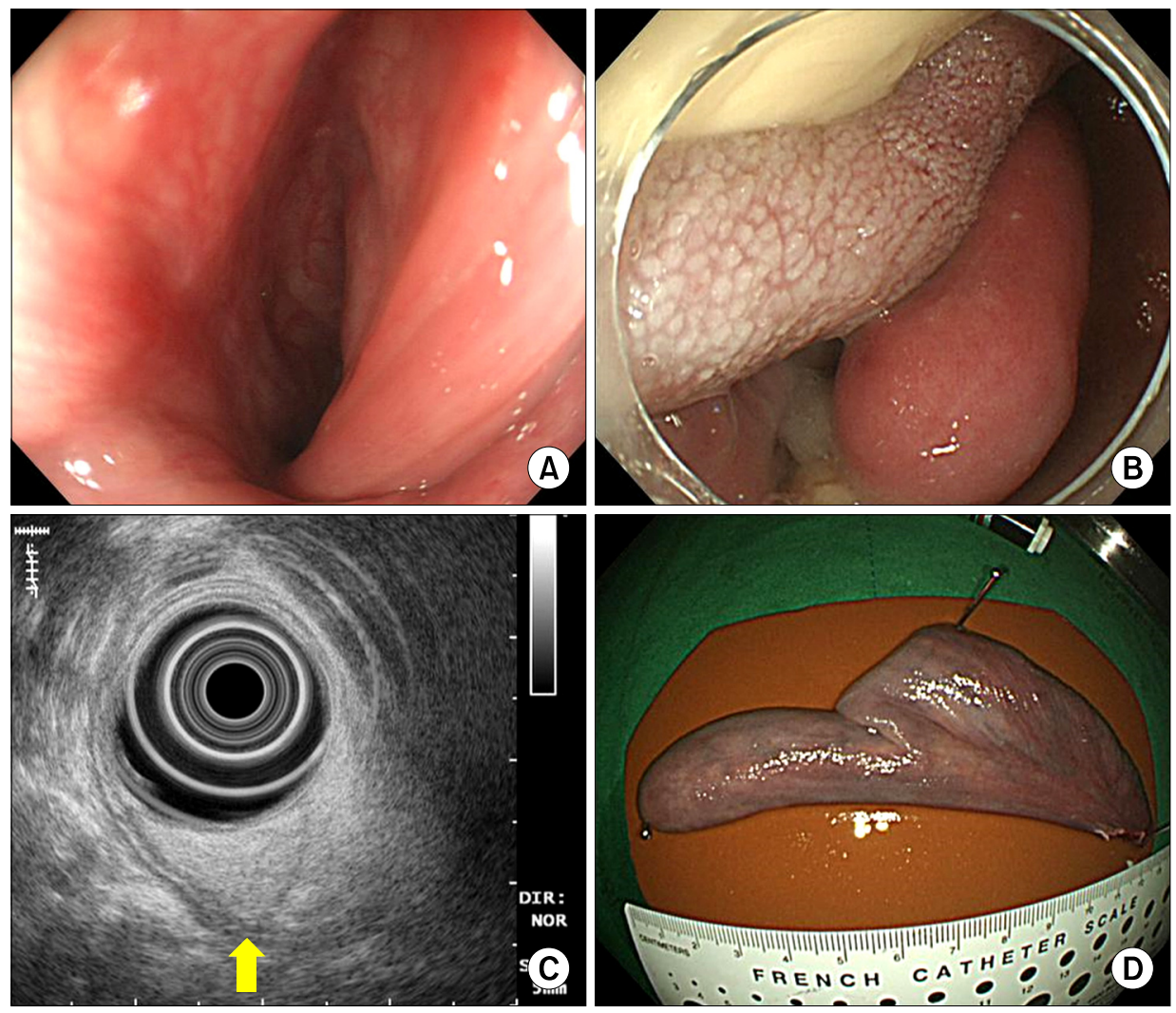

Fig. 1. (A) Endoscopy reveals a huge sized sausage-shaped pedunculated polyp originating from the cervical esophagus, and (B) the polyp is pulled into the oral cavity during examination. (C) Endoscopic ultrasonography shows a hyperechoic homogenous lesion with clear margin on the submucosal layer of the esophagus (arrow). (D) The polyp is successfully resected with a polypectomy snare, and its size is $12 \mathrm{~cm}$.

Received: January 31, 2017 Revised: February 1, 2017 Accepted: February 1, 2017

Corresponding author: Gwang Ha Kim

Department of Internal Medicine, Pusan National University School of Medicine, and Biomedical Research Institute, Pusan National University Hospital, 179 Gudeok-ro, Seo-gu, Busan Department

Tel: +82-51-240-7869, Fax: +82-51-244-8180, E-mail: doc0224@pusan.ac.kr

Copyright $\odot 2017$ Korean College of Helicobacter and Upper Gastrointestinal Research

(.) The Korean Journal of Helicobacter and Upper Gastrointestinal Research is an Open-Access Journal. All articles are distributed under the terms of the Creative Commons Attribution Non-Commercial License (http://creativecommons.org/licenses/by-nc/4.0) which permits unrestricted non-commercial use, distribution, and reproduction in any medium, provided the original work is properly cited. 

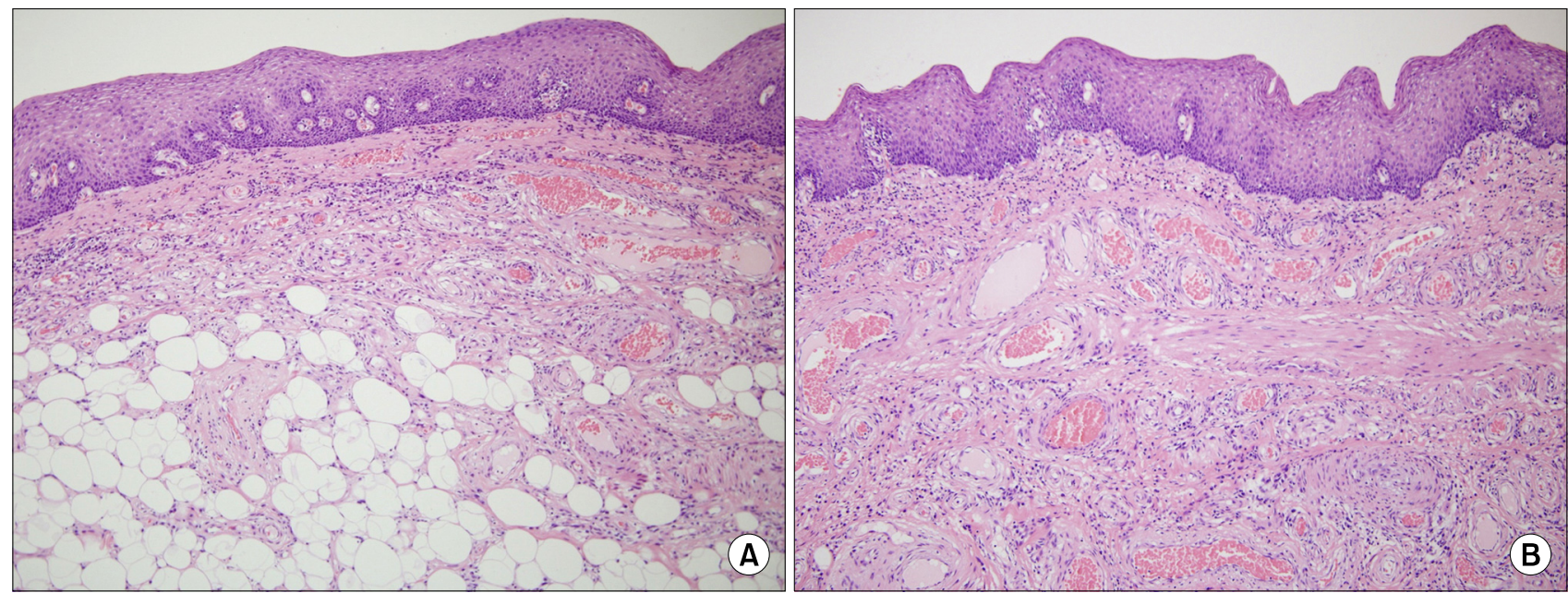

Fig. 2. (A) Histopathologically, the polyp is covered with benign squamous epithelium, and its core is composed of loose fibrous tissues, adipose cells, and blood vessels $(\mathrm{H} \& \mathrm{E}, \times 100)$. (B) On high magnifying view, spindle cells set in collagenous matrix, scattered small blood vessels and inflammatory cells are seen $(\mathrm{H} \& \mathrm{E}, \times 400)$.

Answer: Macroscopically, the mass was a $12-\mathrm{cm}$ pedunculated polypoid lesion covered with normal esophageal mucosa (Fig. 1D). Histopathologically, the lesion was covered with benign squamous epithelium, and its core was composed of loose fibrous tissue, adipose cells, and blood vessels (Fig. 2). We diagnosed the patient with a giant fibrovascular polyp of the esophagus. Upper endoscopy 6 months later revealed no recurrence.

An esophageal fibrovascular polyp is a rare, benign, intraluminal, subepithelial tumor originated from the proximal esophagus. ${ }^{1}$ The treatment modality is chosen after assessing the origin, size, and vascularity of the pedicle. Generally, small polyps $<2 \mathrm{~cm}$ in diameter with a thin pedicle can be removed endoscopically without many complications but this is not recommended in larger tumors (length $>8 \mathrm{~cm})^{2}$ However, after accurate evaluation of the origin of the polyp and the realm of its pedicle under endoscopic ultrasonography, endoscopic resection can be another treatment option for a giant esophageal fibrovascular polyp.

\section{REFERENCES}

1. Lee JW, Kim GH, Kim JK, et al. A case of giant fibrovascular polyp of the esophagus, treated successfully by endoscopic resection. Korean J Gastroenterol 2016;67:253-256.

2. Lee SY, Chan WH, Sivanandan R, Lim DT, Wong WK. Recurrent giant fibrovascular polyp of the esophagus. World J Gastroenterol 2009;15:3697-3700. 